\title{
Women's autonomy in household decision-making: a demographic study in Nepal
}

\author{
Dev R Acharya*1, Jacqueline S Bell2, Padam Simkhada ${ }^{3}$, Edwin R van Teijlingen ${ }^{4}$ and Pramod R Regmi ${ }^{5}$
}

\begin{abstract}
Background: How socio-demographic factors influence women's autonomy in decision making on health care including purchasing goods and visiting family and relatives are very poorly studied in Nepal. This study aims to explore the links between women's household position and their autonomy in decision making.
\end{abstract}

Methods: We used Nepal Demographic Health Survey (NDHS) 2006, which provided data on ever married women aged 15-49 years ( $n=8257$ ). The data consists of women's four types of household decision making; own health care, making major household purchases, making purchase for daily household needs and visits to her family or relatives. A number of socio-demographic variables were used in multivariable logistic regression to examine the relationship of these variables to all four types of decision making.

Results: Women's autonomy in decision making is positively associated with their age, employment and number of living children. Women from rural area and Terai region have less autonomy in decision making in all four types of outcome measure. There is a mixed variation in women's autonomy in the development region across all outcome measures. Western women are more likely to make decision in own health care (1.2-1.6), while they are less likely to purchase daily household needs (0.6-0.9). Women's increased education is positively associated with autonomy in own health care decision making ( $<0.01$ ), however their more schooling (SLC and above) shows non-significance with other outcome measures. Interestingly, rich women are less likely to have autonomy to make decision in own healthcare.

Conclusions: Women from rural area and Terai region needs specific empowerment programme to enable them to be more autonomous in the household decision making. Women's autonomy by education, wealth quintile and development region needs a further social science investigation to observe the variations within each stratum. A more comprehensive strategy can enable women to access community resources, to challenge traditional norms and to access economic resources. This will lead the women to be more autonomous in decision making in the due course.

\section{Background}

Autonomy is the ability to obtain information and make decisions about one's own concerns [1]. It facilitates access to material resources such as food, land, income and other forms of wealth, and social resources such as knowledge, power, prestige within the family and community [2]. Women's autonomy in health-care decisionmaking is extremely important for better maternal and child health outcomes [3], and as an indicator of women's empowerment. Gender-based power inequalities can restrict open communication between partners about

* Correspondence: dra09@aber.ac.uk

1 Aberystwyth University, School of Education \& Lifelong Learning, Old College, King Street, Aberystwyth SY23 2AX, UK

Full list of author information is available at the end of the article reproductive health decisions as well as women's access to reproductive health services. This in turn can contribute to poor health outcomes [4]. Evidence from other developing countries show that women's age and family structure are the strongest determinants of women's authority in decision making [5]. Older women and women in nuclear households are more likely than other women to participate in family decisions.

The socio-cultural context conditions the relationship of women's individual-level characteristics to decisionmaking, and autonomy is a key intervening mediator between women's status and reproductive outcomes [6]. Women have little autonomy in many cultures, so it is important to get (1) a better understanding of the determinants of their decision-making autonomy; (2) and vari- 
ations across regions and socio-cultural contexts in the same country. Previous work has shown that women who have a significant say in reproductive matters tend to be more educated, spend more time on household economic activities and marry later [7]. Several other studies have also shown that the poor tend to be sicker and they utilise care facilities less frequently than their better-off counterparts [8-10]. An African study highlights that ethnicity plays a very important role in shaping a wife's decisionmaking authority and is even more important than other individual-level characteristics as a determinant of authority [11]. Another study emphasises that compared to their husbands' report, wives tend to under-report their household decision-making power. However, educated and employed partners are more likely to participate in the final decisions [12]. The level of women's autonomy also depends on whether wives or husbands are the respondents since it appears that the response categories do not have the same cognitive or semantic meanings for men and women [13]. Limitations to women's physical, sexual, economic, social and political autonomy also affect women's decision-making processes. Population and development programmes are most effective when steps have simultaneously been taken to improve the status of women in the decision making process [1].

In Nepal, as in most parts of South Asia, women commonly have less power and autonomy than men in making decisions about their own health care. Moreover, women often have unequal access to food, education, and health care, limited opportunities to earn incomes, restricted access to, and control over, productive resources, and very few effective legal rights [14]. Women's autonomy in decision making is associated with her ethnicity, deprivation level, urban/rural classification, education, and number of living children [15]. Nepalese women are further disadvantaged by a lack of awareness of opportunities and their legal rights. Their low social status has been identified as a barrier towards national health and population policy progress in Nepal $[16,17]$. Gender equity gives women both increased decisionmaking authority and more modern reproductive outcomes such as to reduce the desire for more children, increase contraceptive use and lower the level of 'unmet need' for contraception [18]. A Nepal Demographic Health Survey (NDHS) shows that women are generally less educated than men [19]. The survey reveals that $37 \%$ of currently married women participated in all four of the important household decisions that were investigated: their own health care, major household purchases, purchases of daily household needs and visits to her family or relatives; while $31 \%$ did not participate in any of these decisions.

\section{Methods}

DHS surveys are nationally representative, populationbased household surveys which provide accurate and internationally comparable data on health indicators in developing countries. DHS surveys are part of the worldwide DHS project whose objective is to improve population and health surveillance [20]. These are conducted around every five years in many low and middle-income countries; in all households from a large representative sample women aged 15-49 (and sometimes men aged 1559) are interviewed. In Nepal, the DHS (2006) survey was conducted under the aegis of the Population Division of the Ministry of Health and Population and implemented by New ERA, a research organisation. Technical support for the survey was provided by Macro International Inc., and it was funded by the United States Agency for International Development (USAID). The survey provides information on fertility levels and determinants, family planning, fertility preferences, infant, child, adult and maternal mortality, maternal and child health, nutrition, knowledge of HIV/AIDS and women's empowerment including socio-economic and background characteristics of households [19]. The aim of this study is to establish the most important socio-background characteristics associated with women's decision-making power.

This study is secondary analysis based on the 2006 Nepal DHS data. The DHS conducted a nationally representative survey of 10,793 women aged 15-49 and 4,397 men aged 15-59; in total 8,257 married women were interviewed about their roles in decision-making. In Nepal, community norms and values affect individual behaviour, so women's age, employment (in the past 12 months), number of living children, residence type (urban or rural), ecological zone (Terai, hill or mountain) and development region were considered as socio-demographic variables. Wealth is described in DHS data by an asset score that is constructed using a principal component analysis of more than 40 asset variables collected by a household questionnaire-these include consumer goods, housing facilities and materials [21]. These asset scores are used to classify women into quintile groups according to the relative wealth of their household. Similarly, women's education has been consistently related to use of maternal and child health services, to positive health outcomes and to insist on participating in family decisions $[22,23]$. Information on level of schooling is collected for women and their partners, so wealth and education could both be included in the analyses. There is a strong sense of family togetherness in Nepal and individual identity is closely tied to that of the family; therefore making decisions often involves complex negotiations [24]. Hence, it is crucial to measure whether a woman is involved in the final decision-making process, using all these socio-background variables. 
The original DHS questionnaire asked about four areas of women's autonomy in decision making. These are own health care, making major household purchases, making purchase for daily household needs and visits to her family or friends. Each question had six responses: (1) respondent alone; (2) respondent and husband/partner; (3) respondent and other person; (4) husband/partner alone; (5) someone else and (6) others. To create a binary variable for the analysis, we grouped the first three responses 1-3 (in which she has some power) and responses 4-6 (in which she has no say in the decision). The socio-background characteristics retrieved from the DHS data set are age, residence, ecological zone, development region, education and wealth quintile which are unchanged for our analysis. However, the background characteristics employment on past 12 months is re-categorised into three categories; not employed, employed for cash and employed not for cash. Similarly, number of living children is re-categorised into four categories $0,1-2$, 3-4 and 5+. Our multivariate regression explores whether socio-background characteristics are independently associated with women's autonomy in decision making. DHS granted permission to extract relevant data from the DHS web pages.

\section{Statistical Analysis}

Analysis is conducted using SPSS version 17.0. Sample weights are used in order to adjust for the sample design; this ensures that the results are representative at a national level. The associations between the predictive (socio-background) factors and four outcome measures of women's decision-making are explored using crosstabulations and the chi-squared test. Factors found to be significantly associated (at a 5\% level; p < 0.05) with the outcome measures were then used in (a) bivariable and (b) multivariable logistic regression to generate odds ratios (ORs) and confidence intervals (95\% CIs). To check the collinearity among predictive factors, the Pearson correlation coefficient $(r)$ is calculated with $\mathrm{p}$-value for significance. A backward-stepwise (BSTEP) method is used in multivariable logistic regression to determine the relative independent factor as a predictor of women's autonomy in decision-making. BSTEP regression starts with all the predictive factors included in the full starting model. It then removes the least significant covariate, that is, the one with the highest p-value, at each step, until all factors have been added. By scrutinising the overall fit of the model, variables will be automatically removed until the optimum model is found.

\section{Results}

\section{Socio-background characteristics}

Table 1 shows the percentage of women who report that they make specific household decisions alone or jointly with their husband. Cross-tabulation result shows that socio- background characteristics are significantly associated with all four types of women's decision making. Of those total respondents, almost half $(47.1 \%)$ of ever-married women took decisions on their own health care alone or jointly with their husband. This proportion compares with $52.8 \%$ on making major household purchases, $57.6 \%$ for making daily household purchases and $56.6 \%$ for visits to family/friends. Participation in own health care decision making gradually increased by age, from $17 \%$ among women aged $15-19$ to $60.3 \%$ in middle-aged women (45-49). Similar age-related decision-making power can be observed for major household purchases (15.5\%-71.3\%), daily purchases (18.0\%-74.6\%) and visits to family and friends (20.1\%-77.0\%). Women in paid employment also have a higher say in decision making.

Women with more living children $(5+)$ have greater participation in decision making for each outcome variable. Making major household purchases is the only exception, as women with three or four children had a slightly higher participation rate $(63.5 \%)$ than those with five or more children (62.5\%). Women from urban areas and the hill region, those in highest wealth quintile and those with levels higher than SLC (School Leaving Certificate) also have a greater say in the decision-making process. Interestingly, women with no education have a higher say compared to those primary or some secondary education for all four outcome variables. Development regions and women's response shows mixed variations across the outcome variables.

\section{Collinearity and bivariate analysis}

The value from Pearson correlation coefficient $(r)$ shows that while many of the covariates are correlated to some degree only age and parity are correlated with a coefficient $>0.5$ (actual value 0.65 ). Each of the four outcome measures of women's autonomy in decision making varies significantly according to socio-background characteristics (Table 2). Women's age shows a positive association with these outcome variables. An exception is the age range 45-49 in major household purchases; being older is more likely to provide autonomy in decision making than being younger.

Women's employment shows a significant relationship with all four outcome measures. Women who work for cash are more likely to participate in health care decision making, making major household purchases, daily household purchases and visits to her family or friends than those who are not employed and those who do not work for cash. Women's increased number of living children has a strong positive association with all the outcome measures in decision making. Women's residence has also a strong association with all four outcome measures in decision making. Rural women are less likely to be 
Table 1: Percent of women's participation in decision making

\begin{tabular}{|c|c|c|c|c|c|}
\hline Background characteristics & $\begin{array}{l}\text { Own health } \\
\text { care (\%) }\end{array}$ & $\begin{array}{l}\text { Major household } \\
\text { purchases (\%) }\end{array}$ & $\begin{array}{l}\text { Purchases for daily } \\
\text { household needs (\%) }\end{array}$ & $\begin{array}{l}\text { Visits to her family } \\
\text { or relatives (\%) }\end{array}$ & Number $\left(n^{w}\right)$ \\
\hline \multicolumn{6}{|l|}{ Age } \\
\hline $15-19$ & 17.0 & 15.5 & 18.0 & 20.1 & 784 \\
\hline $20-24$ & 37.1 & 35.2 & 38.8 & 40.2 & 1,606 \\
\hline $25-29$ & 48.5 & 51.2 & 58.0 & 54.8 & 1,664 \\
\hline $30-34$ & 52.0 & 62.3 & 67.9 & 64.2 & 1,265 \\
\hline $35-39$ & 55.2 & 65.3 & 72.0 & 68.2 & 1,135 \\
\hline $40-44$ & 58.6 & 71.7 & 75.3 & 75.0 & 1,016 \\
\hline $45-49$ & 60.3 & 71.3 & 74.6 & 77.0 & 788 \\
\hline \multicolumn{6}{|l|}{ Employment (past 12 months) } \\
\hline Not employed & 43.5 & 49.7 & 54.5 & 51.9 & 1,376 \\
\hline Employed for cash & 59.6 & 72.7 & 77.4 & 75.4 & 2,438 \\
\hline Employed not for cash & 41.4 & 42.8 & 47.8 & 47.6 & 4,443 \\
\hline \multicolumn{6}{|l|}{ Number of living children } \\
\hline 0 & 21.9 & 21.3 & 23.0 & 26.1 & 860 \\
\hline $1-2$ & 45.2 & 48.3 & 52.8 & 52.3 & 3,364 \\
\hline $3-4$ & 53.7 & 63.5 & 68.5 & 66.2 & 2,831 \\
\hline $5+$ & 55.0 & 62.5 & 70.3 & 67.7 & 1,202 \\
\hline \multicolumn{6}{|l|}{ Residence } \\
\hline Urban & 54.6 & 63.9 & 71.8 & 67.7 & 1,226 \\
\hline Rural & 45.8 & 50.8 & 55.2 & 54.6 & 7,031 \\
\hline \multicolumn{6}{|l|}{ Ecological zone } \\
\hline Mountain & 43.5 & 47.1 & 50.1 & 50.7 & 586 \\
\hline Hill & 50.5 & 57.3 & 63.6 & 63.4 & 3,402 \\
\hline Terai & 44.9 & 49.9 & 53.9 & 51.9 & 4,269 \\
\hline \multicolumn{6}{|l|}{ Development region } \\
\hline Eastern & 46.3 & 53.8 & 61.0 & 57.6 & 1,757 \\
\hline Central & 46.7 & 54.5 & 61.5 & 56.9 & 2,736 \\
\hline Western & 52.5 & 51.0 & 56.3 & 56.9 & 1,602 \\
\hline Mid-western & 45.8 & 50.0 & 56.5 & 60.6 & 976 \\
\hline Far-western & 43.1 & 51.8 & 46.4 & 50.5 & 1,187 \\
\hline \multicolumn{6}{|l|}{ Education } \\
\hline No Education & 47.4 & 54.9 & 59.3 & 58.3 & 5,110 \\
\hline Primary & 44.7 & 49.2 & 54.3 & 52.0 & 1,404 \\
\hline Some secondary & 45.0 & 44.0 & 50.8 & 51.2 & 1,197 \\
\hline SLC and above/higher & 55.8 & 60.7 & 65.4 & 63.4 & 547 \\
\hline \multicolumn{6}{|l|}{ Wealth quintile } \\
\hline Lowest & 45.7 & 51.9 & 56.0 & 57.1 & 1,537 \\
\hline Second & 49.6 & 52.7 & 57.0 & 56.3 & 1,642 \\
\hline Middle & 42.7 & 45.5 & 49.3 & 49.6 & 1,747 \\
\hline Fourth & 44.6 & 49.7 & 55.3 & 53.7 & 1,640 \\
\hline Highest & 53.0 & 64.0 & 70.6 & 66.3 & 1,692 \\
\hline Total & $47.1 \%$ & $52.8 \%$ & $57.6 \%$ & $56.6 \%$ & 8,257 \\
\hline
\end{tabular}

Notes: All chi-square $(\mathrm{X} 2)$ test showed statistically significant association with $\mathrm{p}<0.05$ at $95 \% \mathrm{Cl} ; \mathrm{n}^{\mathrm{w}}=$ weighted totals 
Table 2: Bivariate analysis of women's participation in decision making and socio-background characteristics

\begin{tabular}{|c|c|c|c|c|c|c|c|c|}
\hline \multirow[t]{2}{*}{$\begin{array}{l}\text { Socio-demographic } \\
\text { Characteristics }\end{array}$} & \multicolumn{2}{|c|}{ Own health care } & \multicolumn{2}{|c|}{$\begin{array}{l}\text { Major household } \\
\text { purchases }\end{array}$} & \multicolumn{2}{|c|}{$\begin{array}{l}\text { Purchases daily } \\
\text { household needs }\end{array}$} & \multicolumn{2}{|c|}{$\begin{array}{l}\text { Visits to her family or } \\
\text { relatives }\end{array}$} \\
\hline & Odds Ratios & $95 \% \mathrm{Cl}$ & Odds Ratios & $95 \% \mathrm{Cl}$ & Odds Ratios & $95 \% \mathrm{Cl}$ & Odds Ratios & $95 \% \mathrm{Cl}$ \\
\hline \multicolumn{9}{|l|}{ Age } \\
\hline $15-19$ & 1.0 & & 1.0 & & 1.0 & & 1.0 & \\
\hline $20-24$ & $2.88^{* * *}$ & $(2.33,3.56)$ & $2.95^{* * *}$ & $(2.37,3.67)$ & $2.88^{* * *}$ & $(2.34,3.55)$ & $2.67^{* * *}$ & $(2.18,3.26)$ \\
\hline $25-29$ & $4.60^{* * *}$ & $(3.73,5.67)$ & $5.70^{* * *}$ & $(4.60,7.08)$ & $6.29^{* * *}$ & $(5.12,7.74)$ & $4.82^{* * *}$ & $(3.95,5.89)$ \\
\hline $30-34$ & $5.28^{* * *}$ & $(4.25,6.56)$ & $8.97^{* * *}$ & $(7.17,11.23)$ & $9.65^{* * *}$ & $(7.77,11.99)$ & $7.13^{* * *}$ & $(5.78,8.79)$ \\
\hline $35-39$ & $6.02^{* * *}$ & $(4.83,7.50)$ & $10.22^{* * *}$ & $(8.13,12.84)$ & $11.72 * * *$ & $(9.37,14.65)$ & $8.55^{* * *}$ & $(6.90,10.60)$ \\
\hline $40-44$ & $6.91^{* * *}$ & $(5.52,8.65)$ & $13.77^{* * *}$ & $\begin{array}{l}(10.87 \\
17.45)\end{array}$ & $13.88^{* * *}$ & $\begin{array}{l}(11.01 \\
17.49)\end{array}$ & $11.95^{* * *}$ & $(9.54,14.97)$ \\
\hline $45-49$ & $7.43^{* * *}$ & $(5.88,9.40)$ & $13.48^{* * *}$ & $\begin{array}{l}(10.53 \\
17.27)\end{array}$ & $13.39^{* * *}$ & $\begin{array}{l}(10.50 \\
17.07)\end{array}$ & $13.35^{* * *}$ & $\begin{array}{l}(10.49 \\
16.99)\end{array}$ \\
\hline \multicolumn{9}{|l|}{$\begin{array}{l}\text { Employment (past } \\
12 \text { months) }\end{array}$} \\
\hline Not employed & 1.0 & & 1.0 & & 1.0 & & 1.0 & \\
\hline Employed for cash & $1.91^{* * *}$ & $(1.67,2.19)$ & $2.69^{* * *}$ & $(2.34,3.08)$ & $2.84^{* * *}$ & $(2.46,3.28)$ & $2.84^{* * *}$ & $(2.46,3.26)$ \\
\hline $\begin{array}{l}\text { Employed not for } \\
\text { cash }\end{array}$ & 0.91 & $(0.81,1.03)$ & $0.75^{* * *}$ & $(0.67,0.85)$ & $0.76^{* * *}$ & $(0.67,0.86)$ & $0.84^{* *}$ & $(0.74,0.95)$ \\
\hline \multicolumn{9}{|l|}{$\begin{array}{l}\text { Number of living } \\
\text { children }\end{array}$} \\
\hline 0 & 1.0 & & 1.0 & & 1.0 & & 1.0 & \\
\hline $1-2$ & $2.93^{* * *}$ & $(2.46,3.49)$ & $3.45^{* * *}$ & $(2.89,4.12)$ & $3.75^{* * *}$ & $(3.16,4.46)$ & $3.09^{* * *}$ & $(2.62,3.65)$ \\
\hline $3-4$ & $4.13^{* * *}$ & $(3.46,4.93)$ & $6.43^{* * *}$ & $(5.37,7.70)$ & $7.29^{* * *}$ & $(6.10,8.71)$ & $5.53^{* * *}$ & $(4.66,6.57)$ \\
\hline $5+$ & $4.35^{* * *}$ & $(3.57,5.29)$ & $6.17^{* * *}$ & $(5.05,7.55)$ & $7.92^{* * *}$ & $(6.48,9.69)$ & $5.92^{* * *}$ & $(4.87,7.19)$ \\
\hline \multicolumn{9}{|l|}{ Residence } \\
\hline Urban & 1.0 & & 1.0 & & 1.0 & & 1.0 & \\
\hline Rural & $0.70^{* * *}$ & $(0.62,0.79)$ & $0.58^{* * *}$ & $(0.51,0.66)$ & $0.48^{* * *}$ & $(0.42,0.55)$ & $0.57^{* * *}$ & $(0.50,0.65)$ \\
\hline \multicolumn{9}{|l|}{ Ecological zone } \\
\hline Mountain & 1.0 & & 1.0 & & 1.0 & & 1.0 & \\
\hline Hill & $1.32^{* *}$ & $(1.10,1.57)$ & $1.50^{* * *}$ & $(1.26,1.79)$ & $1.74^{* * *}$ & $(1.46,2.07)$ & $1.68^{* * *}$ & $(1.41,2.01)$ \\
\hline Terai & 1.05 & $(0.89,1.26)$ & 1.12 & $(0.94,1.33)$ & 1.16 & $(0.98,1.38)$ & 1.04 & $(0.88,1.24)$ \\
\hline \multicolumn{9}{|l|}{$\begin{array}{l}\text { Development } \\
\text { region }\end{array}$} \\
\hline Eastern & 1.0 & & 1.0 & & 1.0 & & 1.0 & \\
\hline Central & 1.01 & $(0.90,1.14)$ & 1.02 & $(0.91,1.15)$ & 1.01 & $(0.90,1.15)$ & 0.97 & $(0.85,1.09)$ \\
\hline Western & $1.28^{* * *}$ & $(1.12,1.46)$ & 0.89 & $(0.77,1.02)$ & $0.82^{* *}$ & $(0.71,0.94)$ & 0.97 & $(0.84,1.11)$ \\
\hline Mid-western & 0.98 & $(0.83,1.14)$ & 0.85 & $(0.73,1.00)$ & $0.82^{*}$ & $(0.70,0.97)$ & 1.13 & $(0.96,1.32)$ \\
\hline Far-western & 0.88 & $(0.75,1.02)$ & 0.92 & $(0.79,1.06)$ & $0.55^{* * *}$ & $(0.47,0.64)$ & $0.75^{* * *}$ & $(0.64,0.87)$ \\
\hline \multicolumn{9}{|l|}{ Education } \\
\hline No Education & 1.0 & & 1.0 & & 1.0 & & 1.0 & \\
\hline Primary & 0.89 & $(0.79,1.01)$ & $0.79^{* * *}$ & $(0.70,0.89)$ & $0.81^{* *}$ & $(0.72,0.91)$ & $0.77^{* * *}$ & $(0.68,0.87)$ \\
\hline Some secondary & 0.98 & $(0.87,1.10)$ & $0.73^{* * *}$ & $(0.65,0.82)$ & $0.79 * * *$ & $(0.71,0.89)$ & $0.82^{* *}$ & $(0.73,0.92)$ \\
\hline $\begin{array}{l}\text { Higher (SLC and } \\
\text { above) }\end{array}$ & $1.58^{* *}$ & $(1.20,2.07)$ & $1.41^{*}$ & $(1.07,1.86)$ & $1.34^{*}$ & $(1.01,1.78)$ & $1.38^{*}$ & $(1.04,1.84)$ \\
\hline
\end{tabular}




\begin{tabular}{|c|c|c|c|c|c|c|c|c|}
\hline \multicolumn{9}{|c|}{ Wealth quintile } \\
\hline Poorest & 1.0 & & 1.0 & & 1.0 & & 1.0 & \\
\hline Poorer & $1.16^{*}$ & $(1.01,1.34)$ & 1.03 & $(0.89,1.18)$ & 1.04 & $(0.90,1.19)$ & 0.96 & $(0.84,1.11)$ \\
\hline Middle & 0.88 & $(0.77,1.01)$ & $0.77^{* * *}$ & $(0.67,0.89)$ & $0.76^{* * * *}$ & $(0.66,0.87)$ & $0.73^{* * *}$ & $(0.64,0.84)$ \\
\hline Richer & 0.95 & $(0.83,1.10)$ & 0.91 & $(0.79,1.05)$ & 0.97 & $(0.84,1.12)$ & 0.87 & $(0.75,1.00)$ \\
\hline Richest & $1.33^{* * *}$ & $(1.16,1.53)$ & $1.65^{* * *}$ & $(1.43,1.90)$ & $1.88^{* * *}$ & $(1.63,2.18)$ & $1.47^{* * *}$ & $(1.28,1.70)$ \\
\hline
\end{tabular}

Notes: $\mathrm{OR}=$ odds ratio; $95 \% \mathrm{Cl}=95 \%$ confidence interval; ${ }^{*} \mathrm{p}<0.05 ;{ }^{* *} \mathrm{p}<0.01 ;{ }^{* * *} \mathrm{p}<0.001$.

autonomous $(\mathrm{p}<0.001)$ in decision making compared to their urban counterparts.

Women from the hill region are more likely to have autonomy in decision making in all four outcome measures. Compared to the mountain region, women from the Terai (in south of Nepal) are more likely to be autonomous in decision making; however it is not significantly associated $(p>0.05)$ to all four outcome measures. The development region shows fewer significant relationships in women's decision making. Women from the western development region are more likely to participate in health-care decision making compared to all other regions. In contrast, women from the western, mid-western and far western region are less likely to participate in decision making on daily household needs. Furthermore, a significantly lower proportion of women from the farwestern region reported involvement in decision making around visiting family or relatives $(\mathrm{p}<0.001)$.

Women who are educated to SLC level and above are more likely to participate in all four outcome measures. Interestingly, women with primary and some secondary level education are less likely to participate in decisionmaking around major household purchases, daily household purchases and visits to her family or friends compared to women without education. The richest women are more likely to participate in decision making in all four outcome measures ( $\mathrm{p}<0.001)$. Conversely, middleclass women are significantly less likely to participate in making major household purchases, daily household purchases and visits to her family or relatives compared to all wealth quintiles.

\section{Multivariate analysis}

In this analysis age, employment and number of living children are highly significant to women's autonomy in decision making (Table 3). Age shows a positive relationship to decision making in all four outcomes; younger women are less likely to participate in decision making than older women. Women working for cash are more likely to participate in decision making in all four outcomes $(p<0.001)$ compared to the women who are not employed or paid in kind. The number of living children a woman has also shows a strong positive relationship with decision-making participation. The more children women have, the more likely they participate in decision making in all four outcomes. From the residential viewpoint, rural women are less likely to participate in the decision-making process.

In outcome-1, women from the hill region have a higher participation in decision making around their own health care than those from the mountain and Terai regions; however it is not statistically significant. Women from the western development region have significantly greater influence in health-care decision making for themselves. Education also affects women's ability to make their own decisions. Women with more schooling (SLC and above) are more likely to make decision about their own health care compared to those who have some secondary or primary or no education. It is interesting to note that the richest women are significantly less likely to participate in decision making $(\mathrm{p}<0.01)$ about their own health care compared to all other income groups after adjustment for other factors.

Women's participation in decision making to make major household purchases also has a strong significant association with socio-background characteristics in outcome-2. Here age, employment, number of living children, ecological zone (hill), development region (central), education (primary level) and wealth quintile (middle and richer) are significantly associated with the outcome measure, but rurality is not associated. In outcome- 3 age, employment, number of children, ecological zone (hill) and education (some secondary) have strong odds ratios (ORs) and are significantly associated with the outcome measure. Women from the far western region are the least likely to take part in decision making compared to other regions. The association between schooling level and deciding about daily household purchases yields a non-significant result $(\mathrm{p}>0.05)$ with higher education (SLC and above), however it is significant with primary and having some secondary education. It is clear that women's schooling plays a significant role in taking part in the decision-making; however our finding has created a complex scenario which needs further social-science investigation. Women with middle-wealth quintile are 
also less likely to take part in decision making compared to both richer and the poorest women.

Outcome-4 shows that an increase in age is directly associated to an increase in odds ratios (ORs), which examine the likelihood of women's participation in making decisions to visit her family and friends. As women gets older, they are more likely to take part in the decision making process to visit her family and friends $(\mathrm{p}<0.001)$. Women employed for cash and having 3-4 living children also have a greater say in the decision-making process. Residence (rurality), development region (central) and wealth quintile (middle and richer) have a negative association with the outcome measures; these women are less likely to participate in decision making to visit family and friends.

\section{Discussion}

Increased age, paid employment and having a greater number of living children are all positively associated with women's autonomy in decision making in all four outcomes. Residence (rurality) is less likely to do so in neither the bivariate or multivariate analysis in all outcome measures. In both analyses, women from the hill region are more likely to be autonomous in decision making, except in outcome-1 in the multivariate analysis ( $\mathrm{p}$ > $0.05)$. In bivariate analysis, the development region shows a non-significant result for making major household purchases; however women from the central region are less likely to do so and to decide about purchase daily household needs in the multivariate analysis. Women from the far western region are less likely to be involved in the decision to visit family or relatives in the bivariate analysis, and this pattern has shifted somewhat in the multivariate analysis. Women with more schooling (SLC and above) are more likely to be autonomous in own health care in the both analyses; but they are joined by women with primary and some secondary education in the multivariate analysis. Women with primary education are less likely to decide about major household purchases in the bivariate analysis, while they are more likely to do so in the multivariate analysis.

Women with some secondary (less likely) and more schooling (more likely) are also significantly associated with major household purchase in bivariate analysis, while multivariate analysis does not show such significance. Women with primary and some secondary education are more likely to be autonomous in making daily household purchases and visiting family and friends in multivariate compared to the bivariate analysis. The richest women are significantly more likely to make decisions in all four types of outcome measures in bivariate analysis. However, the multivariate result shows that they are less likely to make decisions in the outcome-1. Poorer women are significantly more likely to be autonomous to make decisions about own health care in the bivariate, while it is non-significant in the multivariate analysis.

\section{Age and number of living children}

There is a significant positive association between women's age and autonomy in decision making among all four measures. This association also exists for the number of living children; women with more living children are more likely to take part in decision making. Autonomy is not a homogenous construct that is represented accurately by a single measure. In Nepal, Bangladesh and India, as women get older they gain autonomy in household decision making [25]. A newly married daughter-inlaw has less decision making power in the household and she is expected to perform household duties under the supervision of her mother-in-law who is the primary decision maker [26]. Some possible factor behind this autonomy is that the older women move out of extended family responsibility, or that women fear that attempts to discuss issues around decision-making to control their own sexuality and reproduction with their husband may lead to aggression [27]. The issue of security and fulfilment of desire also becomes less importance as women gets older and lose contact with their natal kin and become more likely to be independent in decision making. Nevertheless, in some Asian countries, such as Sri Lanka, there is a more collective responsibility around decision-making between men and women in $60.3 \%$ of the households [28].

\section{Employment}

Women's ability to make household decisions is enhanced while they are working. Traditionally Nepalese women were not expected to be in paid employment, so those who work for money used to be from poor families or they work in the household for their family's survival. In addition, some women are employed but not for cash (e.g. kamaiya, hali), they work for landlords (jamindaar), who own large areas of farm land. These women work throughout the year while others work seasonally such as paddy cropping (dhaan ropne), wheat harvesting (gahun kaatne), or herding (gothaalo jaane). They work for subsistence, e.g. food and clothes, and they are mostly from so-called lower casts, and have little decision-making power. Their economic condition stops them from making large or even daily household purchases. The relationship between employment and women's autonomy in decision making appears straightforward. It is clearly shown that women in paid employment are significantly more likely to report to participate in the final decision making compared to those women who are not in paid employment [12].

In Nepal, men often control the household's cash, making it difficult for women to pay for health care or for 
Table 3: Final backward stepwise multivariate analysis model assessing determinants of Nepalese women's autonomy in decision making

\begin{tabular}{|c|c|c|c|c|c|c|c|c|c|}
\hline \multicolumn{2}{|c|}{ Socio-demographic characteristics } & \multicolumn{2}{|c|}{$\begin{array}{c}\text { Outcome-1 } \\
\text { (own health care) }\end{array}$} & \multicolumn{2}{|c|}{$\begin{array}{c}\text { Outcome -2 } \\
\text { (major household purchases) }\end{array}$} & \multicolumn{2}{|c|}{$\begin{array}{c}\text { Outcome -3 } \\
\text { (daily household purchases) }\end{array}$} & \multicolumn{2}{|c|}{$\begin{array}{c}\text { Outcome }-4 \\
\text { (visits to family and friends) }\end{array}$} \\
\hline & & OR & $95 \% \mathrm{Cl}$ & OR & $95 \% \mathrm{Cl}$ & OR & $95 \% \mathrm{Cl}$ & OR & $95 \% \mathrm{Cl}$ \\
\hline \multirow[t]{7}{*}{ Age } & $15-19$ & 1.0 & & 1.0 & & 1.0 & & 1.0 & \\
\hline & $20-24$ & $2.19^{* * *}$ & $(1.74,2.76)$ & $2.06^{* * *}$ & $(1.62,2.61)$ & $1.92^{* * *}$ & $(1.52,2.42)$ & $1.95^{* * *}$ & $(1.56,2.44)$ \\
\hline & $25-29$ & $3.23^{* * *}$ & $(2.54,4.10)$ & $3.37^{* * *}$ & $(2.63,4.32)$ & $3.57^{* * *}$ & $(2.81,4.55)$ & $3.09 * * *$ & $(2.44,3.90)$ \\
\hline & $30-34$ & $3.66^{* * *}$ & $(2.84,4.72)$ & $5.32^{* * *}$ & $(4.09,6.93)$ & $5.18^{* * *}$ & $(4.00,6.72)$ & $4.47^{* * *}$ & $(3.47,5.75)$ \\
\hline & $35-39$ & $4.48^{* * *}$ & $(3.44,5.83)$ & $6.80^{* * *}$ & $(5.16,8.96)$ & $6.93^{* * *}$ & $(5.27,9.11)$ & $6.03^{* * *}$ & $(4.62,7.87)$ \\
\hline & $40-44$ & $5.22^{* * *}$ & $(3.98,6.83)$ & $9.42^{* * *}$ & $(7.08,12.53)$ & $8.11^{* * *}$ & $(6.12,10.76)$ & $8.67^{* * *}$ & $(6.57,11.43)$ \\
\hline & $45-49$ & $5.82^{* * *}$ & $(4.38,7.73)$ & $9.42^{* * *}$ & $(6.97,12.71)$ & $7.72^{* * *}$ & $(5.73,10.40)$ & $9.98^{* * *}$ & $(7.42,13.43)$ \\
\hline \multirow[t]{3}{*}{ Employment } & Not employed & 1.0 & & 1.0 & & 1.0 & & 1.0 & \\
\hline & Employed for cash & $1.41^{* * *}$ & $(1.22,1.63)$ & $1.72^{* * *}$ & $(1.47,2.01)$ & $1.97^{* * *}$ & $(1.67,2.32)$ & $1.86^{* * *}$ & $(1.59,2.18)$ \\
\hline & Employed not for cash & $0.73^{* * *}$ & $(0.63,0.85)$ & $0.53^{* * *}$ & $(0.45,0.62)$ & $0.61^{* * *}$ & $(0.52,0.72)$ & $0.57^{* * *}$ & $(0.48,0.66)$ \\
\hline \multirow[t]{4}{*}{ Number of living children } & 0 & 1.0 & & 1.0 & & 1.0 & & 1.0 & \\
\hline & $1-2$ & $1.81^{* * *}$ & $(1.48,2.21)$ & $1.93^{* * *}$ & $(1.56,2.37)$ & $2.12^{* * *}$ & $(1.73,2.61)$ & $1.78^{* * *}$ & $(1.46,2.17)$ \\
\hline & $3-4$ & $1.97^{* * *}$ & $(1.58,2.45)$ & $2.26^{* * *}$ & $(1.79,2.84)$ & $2.72^{* * *}$ & $(2.16,3.42)$ & $2.06^{* * *}$ & $(1.65,2.57)$ \\
\hline & $5+$ & $1.81^{* * *}$ & $(1.42,2.33)$ & $1.65^{* * *}$ & $(1.27,2.14)$ & $2.41^{* * *}$ & $(1.86,3.14)$ & $1.62^{* * *}$ & $(1.25,2.10)$ \\
\hline Residence & Rural & $0.80^{* *}$ & $(0.69,0.94)$ & 0.87 & $(0.73,1.02)$ & $0.69^{* * *}$ & $(0.58,0.83)$ & $0.77^{* *}$ & $(0.65,0.91)$ \\
\hline \multirow[t]{3}{*}{ Ecological zone } & Mountain & 1.0 & & 1.0 & & 1.0 & & 1.0 & \\
\hline & Hill & 1.10 & $(0.90,1.33)$ & $1.37^{* *}$ & $(1.12,1.68)$ & $1.48^{* * *}$ & $(1.21,1.82)$ & $1.54^{* * *}$ & $(1.26,1.88)$ \\
\hline & Terai & 0.91 & $(0.75,1.10)$ & 0.89 & $(0.73,1.09)$ & 0.91 & $(0.74,1.11)$ & 0.86 & $(0.70,1.05)$ \\
\hline \multirow[t]{5}{*}{ Development region } & Eastern & 1.0 & & 1.0 & & 1.0 & & 1.0 & \\
\hline & Central & 0.95 & $(0.83,1.08)$ & $0.85^{*}$ & $(0.74,0.98)$ & $0.82^{* *}$ & $(0.71,0.94)$ & $0.79^{* *}$ & $(0.69,0.91)$ \\
\hline & Western & $1.39 * * *$ & $(1.20,1.61)$ & 0.92 & $(0.78,1.07)$ & $0.78^{* *}$ & $(0.66,0.92)$ & 0.97 & $(0.83,1.14)$ \\
\hline & Mid-western & 1.07 & $(0.90,1.26)$ & 0.95 & $(0.79,1.13)$ & 0.86 & $(0.72,1.03)$ & $1.26^{*}$ & $(1.05,1.52)$ \\
\hline & Far-western & 0.96 & $(0.82,1.13)$ & 1.11 & $(0.93,1.31)$ & $0.56^{* * *}$ & $(0.47,0.67)$ & 0.85 & $(0.72,1.01)$ \\
\hline \multirow[t]{4}{*}{ Education } & No Education & 1.0 & & 1.0 & & 1.0 & & 1.0 & \\
\hline & Primary & $1.25^{* *}$ & $(1.09,1.43)$ & $1.21^{* *}$ & $(1.05,1.40)$ & $1.24^{* *}$ & $(1.07,1.44)$ & $1.15^{*}$ & $(1.00,1.33)$ \\
\hline & Some secondary & $1.52^{* * *}$ & $(1.32,1.76)$ & 1.14 & $(0.98,1.33)$ & $1.26^{* *}$ & $(1.08,1.47)$ & $1.35^{* * *}$ & $(1.16,1.57)$ \\
\hline & Higher (SLC and above) & $1.85^{* * * *}$ & $(1.36,2.52)$ & 1.28 & $(0.92,1.78)$ & 1.11 & $(0.79,1.57)$ & 1.32 & $(0.94,1.84)$ \\
\hline \multirow[t]{5}{*}{ Wealth quintile } & Poorest & 1.0 & & 1.0 & & 1.0 & & 1.0 & \\
\hline & Poorer & 1.14 & $(0.98,1.32)$ & 1.02 & $(0.87,1.20)$ & 1.02 & $(0.86,1.20)$ & 0.99 & $(0.84,1.16)$ \\
\hline & Middle & $0.83^{*}$ & $(0.71,0.97)$ & $0.72^{* * *}$ & $(0.61,0.85)$ & $0.68^{* * *}$ & $(0.58,0.81)$ & $0.72^{* * *}$ & $(0.61,0.85)$ \\
\hline & Richer & $0.77^{* *}$ & $(0.65,0.91)$ & $0.76^{* *}$ & $(0.64,0.90)$ & $0.75^{* *}$ & $(0.63,0.89)$ & $0.72^{* * *}$ & $(0.61,0.86)$ \\
\hline & Richest & $0.75^{* *}$ & $(0.62,0.91)$ & 1.02 & $(0.83,1.24)$ & 1.05 & $(0.85,1.29)$ & 0.85 & $(0.69,1.04)$ \\
\hline
\end{tabular}

Notes: OR= odds ratio; $95 \% \mathrm{Cl}=95 \%$ confidence interval; ${ }^{*} \mathrm{p}<0.05 ;{ }^{* *} \mathrm{p}<0.01 ;{ }^{* * *} \mathrm{p}<0.001$ 
transportation to health-care facilities. This ultimately limits women's participation in decision making regarding their own health care, household purchases or visiting family or friends. Paid employment appears to empower married women to develop thinking towards participation in decision making. Women's work in the home is not a substitute for work outside the home for the women who desire employment [29]. Further analysis into the benefits and liabilities of women's employment and unemployment in women's participation in decision making is necessary.

\section{Residence}

Rural women are significantly less likely to take part in decision making than urban women. The role of place in decision making is now widely recognised beyond the physical environment, which affects the health of people living there. Individual time-space circumstances interact with conditions in the local area, particularly in communities characterised by poverty and social exclusion [30]. In Nepal, about $80 \%$ of the population live in rural areas, generally within large families. Many are landless, have very small landholdings and are from specific ethnic minority groups such as low caste (dalit) and indigenous peoples (janajati). Geographic isolation of the rural population and their resulting exclusion from basic social services and economic opportunities is a root cause of poverty in Nepal. Many rural women live in severe poverty without any means of improving conditions for themselves and their families, which hinder them from making purchases for household needs. A South Asian study has also mentioned that rural women are less likely to be involved in decision making than urban women [25]. However, in recent years many community-based programmes have been initiated to raise incomes of the rural poor women, connect them to markets and provide economic opportunities through development of rural infrastructure [31]. Such programmes help women to gain access to new social networks and promote their social status, leadership roles, and autonomy in decision making.

\section{Ecological zone}

Topographically, Nepal is divided into three ecological zones e.g. mountain $(35 \%)$ in the northern region, hill $(42 \%)$ in the mid region and the Terai $(23 \%)$ plane in the south. The mountain region is the harsh terrain where transportation and communication facilities are very limited, and only about seven percent of the total population lives here. In contrast, the hill region is densely populated and contains about forty four percent of the total population. The country's most fertile and urbanised area, Kathmandu valley, lies in this region. Unlike the mountain and hill, the terai region in the south is relatively flat, where transportation and communication facilities are more developed. About forty four percent of various types of people live in the Terai, including ethnic groups and others that have roots in India [32]. Our finding shows that the women who live in hilly areas are more likely to participate in decision making compared to the mountain and Terai region women. This suggests that women who live in hilly areas have more autonomy towards the decision making process and their husbands are more likely to support them. Nepal's Terai region is adjacent to the north of India. Women's decision making, freedom from threatening relations with husband, mobility and access to and control over economic resources is highly constrained in north India [33]. A study has clearly noted that the practice of seclusion of women (pardah) is prevalent in Terai region especially for newly married women [24], while women in hills and mountains have more freedom of mobility and greater access to familial and economic resources after marriage.

\section{Development region}

Administratively, Nepal is divided into five development regions- Eastern, Central, Western, Mid-western and Farwestern [34]. However, little research has been conducted on development regions, women's health care and autonomy in decision making. The study findings are varied according to regions and it is hard to come up with possible explanations. For instance, western and mid-western region women have more freedom to make a decision in their own health care. Their role may be limited to making a decision on major household purchase and daily household purchases. However, this is not enough of a rigorous explanation to understand the root cause of such variations. There is very little known or understood about the influences of regions and women' decision making process in Nepal. An India study suggests that the southern region women have more exposure to the outside world, a greater voice in family life and more freedom of movement than do those of the north $[22,35]$. Nepal is largely gender stratified by inheritance and hierarchical relations, and the pattern of female autonomy varies within the regions considerably. Region plays the major conditioning role in women's autonomy in their lives [33]. The dominant behaviour and norms in the region's social system and women's exposure to the outside world provides them more freedom. So, further analysis is needed into whether development region leads to more autonomy for women or other confounding factors affect autonomy. Future research should look at women's autonomy changes across regions.

\section{Education}

Highly educated women are more likely to take part in decision making in their own health care. Traditionally, 
older women (mothers-in-law) make decisions about young women's health care in Nepal [36]. However, perhaps young educated women subtly influence their mothers-in-law's decisions and introduce innovative ideas on decision making at the same time. Education may impart feelings of self-worth and self-confidence, which are more important features in bringing about changes in health-related behaviour than exposure to relevant information [37]. Nevertheless, greater education may reduce the power differential between providers and clients and lower women's unwillingness to seek care. Improvement in educational level and economic conditions is not sufficient to address the gender inequality in South Asia. The latest Human Development Report (2009) clearly describes that Nepal's GDI rank (gender-related development index) is $112^{\text {th }}$ out of 155 countries in the world [38]. There has been an increase in the enrolment of female pupils in Nepalese schools [31], but gender equity has to be incorporated as a core value at the policy level, if education aims to promote the autonomy of women [39]. It has to build up women's capacity to control resources and promote positive self-perceptions, self-confidence, awareness of rights and the ability to achieve them. Supporting community-based programmes increases poor women's participation to develop their capacity, to raise awareness, to build confidence and to develop leadership.

\section{Wealth quintile}

The varied result in decision making suggests that there are other factors which explain the crude association between wealth and women's autonomy in decision making. Women's economic status in the household emerged as an important factor associated with their autonomy in decision making. It seems that an important aspect of this difference lies in the perceptions of household members, particularly in older women, regarding the need of autonomy for women. It also indicates that as the women gets richer; they are less likely to take part in decision making. The ownership and control of property is one of the most critical contributors to the gender gap in economic wellbeing, social status, and empowerment [40]. In Nepal, lack of women's power in the household decision-making process may have contributed to insufficient health care seeking behaviour. About $80 \%$ of Nepal's population still lives in rural areas, characterised by small landholdings, rapid population growth and a fragile ecology, resulting in chronic poverty in many parts of the country [31]. The gender empowerment measure (GEM) determines whether women take an active part in economic and political life. It exposes that Nepal ranks $83^{\text {rd }}$ out of 109 countries in the GEM, highlighting there are inequalities in opportunities among women in selected areas [38].

There are some limitations to this study. In general, men head and control the family unit in Nepalese societ- ies. So, the possibility is that joint decisions have been reached which really meant convincing women to agree with the male head of the household. There is also the probability of recall and interviewer bias in the data set. This is a quantitative survey examining a wide variety of issues so it lacks in-depth information. Since we have conducted multiple logistic regression analysis, we have tried to address the problem of confounding. Intrahousehold attentions are explained to improve husbandwife communication which may strengthen women's influence within households for decision making [41]; however this study lacks such information. It is advised to construct an index combining the four binary variables and use that in the Ordinary Least Squares (OLS) regression. However, the method requires careful investigation and it is considered as a suggestion for future research.

\section{Conclusions}

Many factors affect the ability of women to take part in the decision-making process in the household. Some of these factors relate to the type of decision that is taken and some to the background of the women. The third millennium development goal (MDG) aims to promote gender equality and empower women. It emphasises to increase financial resources to accelerate the goal that equally benefit and empower women and girls [42]. Many intervention programmes exist to improve women's household position in Nepal; however their situation still appears as bleak. Women from middle and richer class have the least decision-making power, which suggests involving them in education and decent employment to lessen their dependency on the family members and husband/partner. In the household, husband-wife relations are central to women's autonomy in decision making, and improved communication between them can deserve sustained support. Women are excluded from decisionmaking by more than just lack of education [43]. Employment and education have always empowered women and brought a positive impact on decision making [44], including reducing the inequalities among men and women. One effective method to do so is to incorporate the notion of empowerment in school curricula [45]. Attention should also be given to those women who do not attend school, through non-formal education. A curriculum for such programmes should be developed with a clear policy framework to reduce differences in education and employment between men and women.

Remote and rural women's involvement in income generation activities is another aspect of women's empowerment, and it can be done by supporting them in entrepreneurship, including improved access to property and economic assets, training, microfinance and markets. There is a need for a specially designed empowerment programme for women in the Terai, where gender-strati- 
fied setting is high and women's low autonomy is largely the result of traditional factors. Above all, it is strongly argued that women's autonomy should enhance not just her education and employment [6]. Somewhat, a more comprehensive strategy must be sought that could raise women's gender consciousness, enable them to access community resources and provide support for challenging traditional norms which cause gender inequalities $[31,46,47]$. Nepalese programme and policy initiatives should develop a clear policy foundation that should be crucial to empower women to take part in decision-making processes in the household. Moreover, enhancing their access to and control over economic resources and enabling them to establish and realise their rights are also essential means to empower them to be more autonomous in decision making.

\section{Competing interests}

The authors declare that they have no competing interests.

\section{Authors' contributions}

DRA and PS jointly developed the principal idea for the analysis. DRA and JSB obtained the data and did the statistical analysis. DRA further analysed, reviewed and drafted the paper. JSB, PS, EVT and PRR supervised the data and commented on the draft. All authors read and made substantial contributions to draughts and approved the final manuscript.

\section{Acknowledgements}

We would like to thank the MEASURE-DHS Calverton MD, for their permission to use Nepal DHS 2006. Thanks also go to Bibha Simkhada, a doctoral student in the University of Aberdeen, for her valuable comments and feedback.

\section{Author Details}

${ }^{1}$ Aberystwyth University, School of Education \& Lifelong Learning, Old College, King Street, Aberystwyth SY23 2AX, UK, 2University of Aberdeen, Immpact, Institute of Applied Health Sciences, Foresterhill, Aberdeen AB25 2ZD, UK, ${ }^{3}$ University of Sheffield, School of Health and Related Research (ScHARR), Regent Court, 30 Regent Street, Sheffield S1 4DA, UK, “Bournemouth University, School of Health and Social Care, Maternal \& Perinatal Health Research, Royal London House, Christchurch Road, Bournemouth BH1 3LT, UK and 5 University of Aberdeen, Department of Public Health, Foresterhill, Aberdeen AB25 2ZD, UK

Received: 23 March 2010 Accepted: 15 July 2010

Published: 15 July 2010

\section{References}

1. Dyson T, Moore M: On kinship structure, female autonomy, and demographic behaviour in India. Population and Development Review 1983, 9:35-60.

2. Dixon RB: Rural Women at Work: Strategies for Development in South Asia. Baltimore: Johns Hopkins University Press; 1978.

3. International Conference on Population and Development 1994 [http:/ /www.un.org/ecosocdev/geninfo/populatin/icpd.htm]. accessed on 14/ $11 / 2009$

4. Power in Sexual Relationships: An Opening Dialogue Among Reproductive Health Professionals 2001 [http://www.popcouncil.org/ pdfs/power.pdf]. accessed on 02/10/2009

5. Sathar ZA, Shahnaz K: Women's autonomy in the context of rural Pakistan. The Pakistan Development Review 2000, 39:89-110

6. Jejeebhoy S: Women's autonomy in rural India: Its dimensions, determinants, and the influence of context. In Women's Empowerment and Demographic Processes: Moving Beyond Cairo 1st edition. Edited by: Presser HB, Sen G. New York: Oxford University Press; 2000.
7. Jin $\mathrm{H}$ : A study of rural women's decision making power on reproduction and fertility. Chinese Journal of Population Science 1995, 7:241-257.

8. Fever and its Treatment among the more and less Poor in Sub-Saharan Africa 2002 [http://www-wds.worldbank.org/external/default/ WDSContentServer/IW3P/IB/2002/04/05/000094946 0203220527375/ additional/135535322 20041117182125.pdf. accessed on 04/01/2010

9. Gwatkin D: How much would poor people gain from faster progress towards the millennium development goals for health? The Lancet 2005, 365:813-7.

10. Njau D, Goodman C, Kachur SP, Palmer N, Khatib RA, Abdulla S, Mills A Bloland P: Fever treatment and household wealth: the challenge posed for rolling out combination therapy for malaria. Tropical Medicine and International Health 2006, 11:299-313.

11. Kritz MM, Adebusoye PM: Determinants of women's decision-making authority in Nigeria: the ethnic dimension. Sociological Forum 1999, 14:399-424.

12. Becker S, Fonseca-Becker F, Schenck-Yglesias C: Husbands' and wives' reports of women's decision-making power in Western Guatemala and their effects on preventive health behaviours. Social Science \& Medicine 2006, 62(9):2313-2326

13. Ghuman SJ, Lee HJ, Smith HL: Measurement of women's autonomy according to women and their husbands: Results from five Asian countries. Social Science Research 2006, 35(1):1-28.

14. ADB to Promote Greater Empowerment for Nepal's Most Disadvantaged Women 2004 [http://www.adb.org/Documents/News/ 2004/nr2004177.asp]. accessed on 07/11/2009

15. Kabeer N: Resources, agency, achievements: reflections on the measurement of women's empowerment. Development and Change 2002, 30:435-464.

16. Women's Empowerment Programme Nepal 2009 [http:// asiafoundation.org/resources/pdfs/WEPNepal.pdf]. accessed on 18/11/ 2009

17. Tuladhar J: Women, health and population policies. Nepal Population and Development Journal 1997:19-36.

18. Morgan SP, Niraula BB: Gender inequality and fertility in two Nepali villages. Population and Development Review 1995, 21:541-561.

19. Nepal Demographic and Health Survey 2006 [http:// www.measuredhs.com/pubs/pdf/FR191/FR191.pdf]. accessed on 17/08/ 2009

20. Demographic and Health Surveys [http://www.measuredhs.com] accessed on 17/06/2009

21. Gwatkin DR, Rutstein S, Johnson K, Suliman E, Wagstaff A, Amozou A: Socio-economic differences in health, nutrition and population. The Journal of American Medical Association (JAMA) 2007, 298:1943-1944.

22. Jejeebhoy S: Women's Education, Autonomy and Reproductive Behaviour: Experiences from Developing Countries. New York: Oxford University Press; 2002.

23. Caldwell JC, Caldwell P: What have we learnt about the cultural social and behavioural determinants of health? From selected readings to the first health transition workshop. Health Transition Centre 1991, 1:3-17.

24. Acharya $\mathrm{M}$, Bennett $\mathrm{L}$ : Women and the subsistence sector: economic participation and household decision making in Nepal, a working paper (526) for the World Bank, Washington DC. 1983.

25. Senarath $U$, Gunawardena NS: Women's autonomy in decision making for health care in south Asia. Asia-Pacific Journal of Public Health 2009, 21:137-143

26. Dali SM, Thapa M, Shrestha S: Education for Nepalese women to provide improved care for their childbearing daughters-in-law. World Health Forum 1999, 13:353-354

27. Hof $C$, Ritchers A: Exploring intersections between teenage pregnancy and gender violence: lessons from Zimbabwe. African Journal of Reproductive Health 1995, 3:51-65.

28. Weerasinghe MC: Health seeking behaviour pattern in rural population in a district of Sri Lanka. In MD Thesis University of Colombo, Institute of Medicine; 2005

29. Schwefel D: Unemployment, health and health services in Germanspeaking countries. Social Science and Medicine 1986, 22:409-430.

30. Young R: Prioritising family health needs: a time-space analysis of women's health-related behaviours. Social Science and Medicine 1999, 48:797-813 
31. Asian Development Bank and Nepal [http://www.adb.org/Documents/ Fact Sheets/NEP.pdf]. accessed on 03/03/2010

32. Central Bureau of Statistics: Statistical Pocket Book. Kathmandu, Nepal 2006.

33. Jejeebhoy S, Sathar ZA: Women's autonomy in India and Pakistan: the influence of religion and region. Population and Development Review 2001, 27:687-712.

34. Central Bureau of Statistics: Nepal in Figures. Kathmandu, Nepal 2006.

35. Basu AM: Culture, the Status of Women, and Demographic Behaviour: Illustrated with the Case of India. Oxford: Clarendon Press; 1992.

36. Mullany BC, Hinde MJ, Becker S: Can women's autonomy impede male involvement in pregnancy health in Kathmandu, Nepal? Social Science and Medicine 2005, 61:1993-2006.

37. Chanana K: Education attainment, status production and women's autonomy: a study of two generations of Punjabi women in New Delhi. In Girls'Schooling, Women's Autonomy and Fertility Change in South Asia Edited by: Jeffery R, Basu AM. New Delhi, Sage Publications; 1996:107-132.

38. Human Development Report Nepal 2009 [http://hdrstats.undp.org/en/ countries/country fact sheets/cty fs NPL.html]. accessed on 04/032010

39. Jayaweera S: Higher education and the economic and social empowerment of women-the Asian experience. A Journal of Comparative and International Education 1997, 27:245-261.

40. Agarwal B: Gender and command over property: a critical gap in economic analysis and policy in South Asia. World Development 1994, 22:1455-1478.

41. Furuta M, Salway S: Women's position within the household as a determinant of maternal health care use in Nepal. International Family Planning Perspectives 2006, 32:17-27.

42. End Poverty 2015, Millennium Development Goal [http://www.un.org/ millenniumgoals/gender.shtml]. accessed on 07/03/2010

43. UNIFEM Women, Poverty and Economics http://unifem.org.sg/ gender issues datasheet 1.shtml]. accessed on 23/06/2010

44. Mumtaz Z, Salway SM: Gender, pregnancy and the uptake of antenatal care services in Pakistan. Sociology of Health and IIIness 2007, 29:1-26.

45. Speizer I, Magnani R, Colvin C: The effectiveness of adolescent reproductive health interventions in developing countries: a review of the evidence. Journal of Adolescent Health 2003, 33:324-348.

46. International women's day 2010 [http://www.un.org/en/events/ women/iwd/2010/sg message.shtml]. accessed on 10/03/2010

47. Batliwala S: The meaning of women's empowerment: new concepts from action. In Population Policies Reconsidered: Health, Empowerment, and Rights Edited by: Sen G, Germain A, Chen LC. Cambridge, MA: Harvard Centre for Population and Development Studies; 1994.

doi: $10.1186 / 1742-4755-7-15$

Cite this article as: Acharya et al., Women's autonomy in household decision-making: a demographic study in Nepal Reproductive Health 2010, 7:15

\section{Submit your next manuscript to BioMed Central} and take full advantage of:

- Convenient online submission

- Thorough peer review

- No space constraints or color figure charges

- Immediate publication on acceptance

- Inclusion in PubMed, CAS, Scopus and Google Scholar

- Research which is freely available for redistribution

Submit your manuscript at www.biomedcentral.com/submit
Ciomed Central 